NBER WORKING PAPER SERIES

\title{
SCHOOL LUNCH QUALITY AND ACADEMIC PERFORMANCE
}

\author{
Michael L. Anderson \\ Justin Gallagher \\ Elizabeth Ramirez Ritchie \\ Working Paper 23218 \\ http://www.nber.org/papers/w23218 \\ NATIONAL BUREAU OF ECONOMIC RESEARCH \\ 1050 Massachusetts Avenue \\ Cambridge, MA 02138 \\ March 2017
}

The authors would like to thank Peter Hinrichs, Scott Imberman, Aaron Sojourner, and Mary Zaki for helpful comments on this project. The authors also thank Paul Fisher, Anthony Gatti, Sarah Mattson, Jonathon Mobley, and Aaron Weisberg for outstanding research assistance. A special thanks to Grace Chan and Pat Crawford at the Nutrition Policy Institute for their analysis of the nutritional content of the lunches o ered by the school lunch vendors. This work was supported by the Giannini Foundation of Agricultural Economics and the USDA National Institute of Food and Agriculture, Hatch Project 233535. The views expressed herein are those of the authors and do not necessarily reflect the views of the National Bureau of Economic Research.

NBER working papers are circulated for discussion and comment purposes. They have not been peer-reviewed or been subject to the review by the NBER Board of Directors that accompanies official NBER publications.

(C) 2017 by Michael L. Anderson, Justin Gallagher, and Elizabeth Ramirez Ritchie. All rights reserved. Short sections of text, not to exceed two paragraphs, may be quoted without explicit permission provided that full credit, including $\left({ }^{\circ}\right.$ notice, is given to the source. 
School Lunch Quality and Academic Performance

Michael L. Anderson, Justin Gallagher, and Elizabeth Ramirez Ritchie

NBER Working Paper No. 23218

March 2017

JEL No. I12,I20

\begin{abstract}
$\underline{\text { ABSTRACT }}$
Improving the nutritional content of public school meals is a topic of intense policy interest. A main motivation is the health of school children, and, in particular, the rising childhood obesity rate. Medical and nutrition literature has long argued that a healthy diet can have a second important impact: improved cognitive function. In this paper, we test whether offering healthier lunches affects student achievement as measured by test scores. Our sample includes all California (CA) public schools over a five-year period. We estimate difference-in-difference style regressions using variation that takes advantage of frequent lunch vendor contract turnover. Students at schools that contract with a healthy school lunch vendor score higher on CA state achievement tests, with larger test score increases for students who are eligible for reduced price or free school lunches. We do not find any evidence that healthier school lunches lead to a decrease in obesity rates.

Michael L. Anderson

Department of Agricultural and Resource Economics

207 Giannini Hall, MC 3310

University of California, Berkeley

Berkeley, CA 94720

and NBER

mlanderson@berkeley.edu

Justin Gallagher

Department of Economics

Weatherhead School of Management

Case Western Reserve University

10900 Euclid Avenue

Cleveland, $\mathrm{OH}$ 44106-7235

jpg75@ case.edu

Elizabeth Ramirez Ritchie

207 Giannini Hall

MC 3310

University of California, Berkeley

Berkeley, CA 94720-3310

elizabeth.ramirez@berkeley.edu
\end{abstract}




\section{Introduction}

Improving the nutritional content of public school meals in the US is a topic of intense policy interest (Confessore [2014]). A primary motivation underlying these nutritional improvements is to increase student health and reduce childhood obesity rates. A question of comparable import, however, is whether healthier meals affect student achievement. Recent research demonstrates that the provision of subsidized school meals can significantly increase school test scores (Figlio and Winicki [2005]; Dotter [2014]; Imberman and Kugler [2014]; Frisvold [2015]), but to date little evidence exists on how the quality of school meals affects student achievement.

To answer the question of whether the quality of school meals affects student achievement, we exploit longitudinal variation in California school districts' meal vendors and estimate difference-in-differences type specifications. We combine two principal data sets from the California Department of Education, one covering breakfast and lunch vendors at the school level and the other containing school-by-grade-level standardized test results. Our five-year panel dataset includes all CA public elementary, middle, and high schools with non-missing state test score data (about 9,700 schools). For each California

public school, we observe whether the district in which the school is located had an outside contract with a meal provider for the school year, and, if so, the name of the provider and the type of contract. The vast majority of schools provide meals using "in-house" staff, but a significant and growing fraction (approximately 12\%) contract with outside vendors to provide meals. Crucially for our research design, there is substantial turnover in vendors at the 
school district level during our sample period.

A central obstacle in estimating the effects of healthy meal vendors on academic performance is accurate measurement of nutritional quality. We measure the nutritional quality of vendor school lunches using an enhanced version of the Healthy Eating Index (HEI). The HEI is a continuous score ranging from 0 to 100 that uses a well-established food component analysis to determine how well food offerings (or diets) match the Dietary Guidelines for Americans (e.g., Guenther et al. [2013b]). HEI is the measure of diet quality preferred by the United States Department of Agriculture (USDA) (USDA [2006]) and has previously been used by researchers to evaluate menus at fast-food restaurants and child-care centers. We contracted with trained nutritionists at the Nutrition Policy Institute to calculate vendor HEI scores for this project. $^{1}$ Using their scores, we classify a vendor as healthy if its HEI score is above the median score among all vendors in our sample, and as standard otherwise.

We find that contracting with a healthy meal vendor increases test scores by 0.03 to 0.04 standard deviations relative to in-school meal provision, after conditioning on school-by-grade and year fixed effects. This result is statistically significant and robust to the inclusion or exclusion of our time-varying covariates. When estimating effects separately for economically disadvantaged and non-disadvantaged students, we find modest evidence that the effect of contracting with a healthy vendor is larger for economically disadvantaged students than for non-disadvantaged students. Moreover, while there is no sta-

\footnotetext{
${ }^{1}$ http://npi.ucanr.edu/About_Us/
} 
tistically or economically significant effect of standard vendors on the student population as a whole, disadvantaged students do experience a statistically significant increase in test scores when a district contracts with a standard vendor, relative to in-school meal provision. This result may occur because economically disadvantaged students qualify for the National School Lunch Program (NSLP) and are more likely to eat school-provided meals. These students may also have poorer nutritional intake when eating meals that are not school-provided.

To test whether differential trends in test scores between schools that contract with healthy vendors and other schools drive our results, we conduct a series of tests in which we code a "placebo" treatment that activates one year prior to the year in which a school actually contracts with a healthy vendor. We find that the coefficient on the placebo treatment is close to zero (less than 0.01 standard deviations) and statistically insignificant, implying that test scores are not trending differently prior to the year of the contract for schools that contract with healthy vendors. We also conduct a series of falsification tests in which we use our time-varying covariates as dependent variables. We find that changes in observable characteristics of schools are uncorrelated with new vendor contracts.

Although our estimated effects of 0.03 to 0.04 standard deviations are modest on an absolute scale, they are highly cost-effective for a human capital investment. We calculate a plausible upper bound on the cost of contracting with a healthy lunch provider, relative to in-house meal preparation, of approximately $\$ 80(2013 \$)$ per test-taker per school year. Using our preferred 
estimate of 0.036 standard deviations, this implies that it costs (at most) $\$ 222$ per year to raise a student's test score by 0.1 standard deviations. Despite assuming high costs, the cost effectiveness of contracting with healthy vendors matches the most cost-effective policies highlighted by Jacob and Rockoff [2011], and it compares very favorably when measured against interventions that achieve larger absolute effects, such as the Tennessee STAR class size reduction experiment (Krueger [1999]).

\section{$2 \quad$ Background and Data}

\subsection{Related Literature}

There is a large medical and nutrition literature examining the link between diet and cognitive development, and between diet and cognitive function (e.g., Bryan et al. [2004]; Sorhaindo and Feinstein [2006]; Gomez-Pinilla [2008]; Nandi et al. [2015]). Sorhaindo and Feinstein [2006] review existing research on the link between child nutrition and academic achievement and highlight how nutrition can affect learning through three channels: physical development (e.g., sight), cognition (e.g., concentration, memory), and behavior (e.g., hyperactivity). Gomez-Pinilla [2008] outlines some of the biological mechanisms regarding how both an increase in calories and an improvement in diet quality and nutrient composition can affect cognition. For example, "diets that are high in saturated fat are becoming notorious for reducing molecular substrates that support cognitive processing and increasing the risk of neurological dysfunction in both humans and animals" (Gomez-Pinilla [2008], p569). Most 
of the direct evidence on how nutrition affects academic achievement among school-age children comes from studies of children in developing countries (Alderman et al. [2007] and Glewwe and Miguel [2008] provide reviews).

A number of recent studies have estimated the effect of increased availability of either breakfast or lunch under the NSLP on student test scores in the US. Many of these studies find evidence that improved access to breakfast or lunch increased test scores (e.g., Figlio and Winicki [2005]; Dotter [2014]; Imberman and Kugler [2014]; Frisvold [2015]), while others find no effect (e.g., Leos-Urbel et al. [2013]; Schanzenbach and Zaki [2014]). In all of these studies, the main hypothesized channel between the increased take-up of the school breakfast and lunch programs and test scores is an increase in calories consumed. The NSLP may also have broadly increased educational attainment by inducing children to attend school (Hinrichs [2010]).

Our paper focuses on the nutritional quality of the calories provided. We are aware of just one other study that estimates the effect of food quality on academic test scores. Belot and James [2011] estimate the effect of introducing a new, healthier school lunch menu in 80 schools during the same academic year in one borough in London, as compared to schools in a neighboring borough. The authors estimate a positive effect on test scores for elementary school students, but, oddly, find that the effect is larger for higher socioeconomic students who do not qualify for reduced price or free school lunch.

Relative to Belot and James [2011], we provide evidence from a much larger sample that includes all CA public schools (roughly 9,700 schools), of which 1,192 contract with an outside lunch provider. Our estimation approach uses 
within-grade and school variation in the introduction and removal of healthy and unhealthy lunch providers that occurs in each of the five years of our panel. Thus, we can account for constant unobserved grade-by-school effects. Further, the staggered timing of the lunch contracts allows us to flexibly control for unobserved (calendar) time effects, and to conduct a series of robustness checks regarding the exogeneity of the timing of the contracts. Finally, like Belot and James [2011], we estimate the effect of healthier school lunches on the number of lunches served; however, unlike Belot and James [2011], we are also able to test whether healthier lunch provision changes obesity rates.

\subsection{Data Sources}

The data for this project come from the State of California Department of Education. We use information on school-level breakfast and lunch vendors, and school-by-grade-level standardized test results. We describe each type of information in detail below.

\subsubsection{Vendor Data}

The vendor meal contract information is provided by the California Department of Education for the school years 2008-2009 to 2012-2013. ${ }^{2}$ All food vendor contracts with public (K-12) schools in California must be approved by the CA Department of Education. The CA Department of Education retains a list of the schools that contract with an outside meal provider for each

\footnotetext{
${ }^{2}$ The data were received as part of an official information request. We thank Rochelle Crossen for her assistance in facilitating the request and in interpreting the data. Contract information for school years prior to 2008-2009 was not retained when the CA Department of Education switched computer database systems.
} 
school year, the name of the provider, and the type of contract. A total of 145 school districts covering 1,192 schools contracted with a total of 46 different vendors during our sample period. We merged the food vendor contract information with the list of all public schools (including charter schools) operating in CA during this time period to create our estimation panel. Overall, $12 \%$ of CA public schools contracted for at least one academic year with an outside company to provide school lunch.

Appendix Table A1 lists the 45 vendors and the percent of students served by each vendor (conditional on being served by any vendor). For each vendor, we first calculate the number of (STAR) test-takers in districts that are being served by that vendor. This vendor-level total is then divided by the total number of test-takers being served by outside vendors. A single vendor serves just over $50 \%$ of the students. Altogether, the vendors with the ten largest student test-taker market shares serve $97.4 \%$ of CA students enrolled in schools that contract with outside school lunch providers.

Nearly all of the contracts (97\%) are signed in the summer and cover the entire academic school year. ${ }^{3}$ The CA Department of Education classifies all food provision contracts as one of four types: Vendor, Food Service Management Company (FSMC), Food Service Consulting Company (FSCC), and School Food Authority (SFA). A Vendor contract is when a school contracts with a private company to provide meals, but school employees (i.e., cafeteria staff) still handle and serve the food, including any additional prepping

\footnotetext{
${ }^{3} \mathrm{~A}$ small number of contracts cover less than the complete school year. These contracts correspond to the calendar year and thus cover only a fraction of the school year (AugustDecember or January-June). Estimation results are insensitive to the inclusion of these contracts in our sample.
} 
and cooking. In a FSMC contract, a private company prepares the meals and assists in staffing the school with cafeteria workers who serve the meals. In a FSCC contract, a private company provides "consulting services" on meal preparation and staffing, but does not provide any personnel for the jobs. SFA contracts usually denote that one public school district contracts with another district for meal provision. SFA contracts are unusual and account for just $1 \%$ of the contract-grade years. We do not distinguish between the four types of contracts in the main analysis of the paper and, unless specified, we refer to all such companies as "vendors."

Detailed vendor contract information is available for a subset of the contracts. Contract details include meals provided (either lunch or both breakfast and lunch), the dollar value of the contract, the number of other contract bidders (if any), the names of the companies which bid for the contract and were not selected, the dollar value of losing contracts, and the method by which the contract bids were solicited (i.e., sealed bid or negotiation). In the main analysis, we do not distinguish between vendors that provide both lunch and breakfast and those that provide only lunch, as this information is only available for a minority of the contracts. ${ }^{4}$ We use the contract bid information to help construct counterfactual estimates for the cost to improve state test scores by contracting with healthy lunch providers.

\footnotetext{
${ }^{4}$ The contract details are not available for all contracts for two reasons. First, school districts are only required to provide contract details to the state for the first year of a new contract. A contract can be renewed up to four times without having to issue a new contract. Second, school officials enter the contract information via a software program that electronically stores the data in the CA Department of Education database. In practice, many of the data fields are missing for most of the new contracts. This is because, until recently, the CA Department of Education didn't have the staff to review the contract price and bid data entered into the system.
} 
The nutritional quality of the vendor school lunches is assessed using the Healthy Eating Index (HEI). HEI is the US Department of Agriculture's (USDA) preferred measure of diet quality (USDA [2006]), and the USDA uses it to "examine relationships between diet and health-related outcomes, and to assess the quality of food assistance packages, menus, and the US food supply" (USDA [2016]). HEI has been used by researchers to assess both individual diets (e.g., Volpe and Okrent [2012]; Guenther et al. [2013a]) and the diets of subpopulations (e.g., Hurley et al. [2009]; Manios et al. [2009]), as well as food offerings at fast food restaurants (e.g., Reedy et al. [2010]) and child-care centers (e.g., Erinosho et al. [2013]). The HEI scores range from 0 to 100, with higher scores representing healthier diets (or food offerings). Scores are calculated via a food component analysis done on a per calorie basis (Guenther et al. $[2013 b])$.

The vendor HEI scores were calculated by nutritionists at the Nutrition Policy Institute using sample school lunch menus. The Appendix provides details of the HEI score calculations and examples of menus used as part of the analysis. Menu information was not available for all of the vendors, and as a result some vendors were not assigned HEI scores. Appendix Table 1 shows that this is mostly the case for vendors that contract infrequently with schools. Overall, HEI scores are calculated for $87.4 \%$ of student test-takers served under vendor contracts. The median vendor HEI score in our sample is 62.3. This median vendor score is similar to the average HEI score, 63.8, for the US population age two and older (USDA [2006], p.21). To better discriminate between healthy and standard vendors, the nutritionists recommended that 
we supplement the HEI score with additional information from the sample menus. The supplemental scores provided additional points for healthy options that exceeded USDA requirements (e.g., salad bars) and subtracted points for unhealthy options (e.g., fast foods, certain processed foods, and high-sugar foods). We define a vendor as healthy if it has a vendor HEI score above the median vendor score. ${ }^{5}$ Alternative classifications (e.g., coding any vendor with an HEI above the mean vendor HEI score) generate similar results. Vendors with below-median scores or with unknown scores are classified as standard. This should not bias our estimates of the effects of healthy vendors, but it could modestly bias our estimates of the effects of standard vendors, since a minority of vendors classified as standard may in fact be healthy.

\subsubsection{Academic Test Data and Covariates}

To measure academic achievement, we use California's Standardized Testing and Reporting (STAR) test data. The STAR test is administered to all students in grades 2 through 11 each spring, toward the end of the academic year. The publicly available test scores are aggregated at the grade-by-school level. We use test score data from 1998 through 2013. Beginning with the 201314 school year, STAR testing was replaced with the California Assessment of Student Performance and Progress test.

The STAR test includes four core subject area tests (English/Language

\footnotetext{
${ }^{5}$ Specifically, we use the vendor HEI score supplemented with the additional information described above. In preparing their analysis, the nutritionists assumed that all vendors met the baseline USDA requirements, as they are obligated by law to do so. They also assumed that the average meal contains 650 calories, and they matched food items to foods available in the USDA food database. The classification of vendors as healthy or standard was not sensitive to any of these choices.
} 
Arts, Mathematics, History/Social Sciences, and Science) and a set of end-ofcourse examinations (e.g., Algebra II, Biology). We create a composite test score each year for each school-grade by calculating the average test score across all of the STAR subjects and the end-of-course tests taken by students in a particular grade in each school. We use the standard deviation of each test (which differs by grade and year of test) to standardize each subject and end-of-course test score before combining the scores into a single composite score. ${ }^{6}$

Average test scores are also available separately for students who qualify for reduced price and/or free school lunch under the NSLP. A student is eligible for a free school lunch if his family's income is less than $130 \%$ of the poverty level, and a reduced price lunch if her family's income is between $130 \%$ and $185 \%$ of the poverty level. The CA Department of Education refers to these students as "economically disadvantaged" (California Department of Education [2011], p. 48). Students eligible for the reduced price or free lunches are the students most likely to eat the lunch offered at the school, for two reasons: the price is lower for them than it is for ineligible students, and eligible students are less likely to have other lunch options. Furthermore, the nutritional quality of their home-provided meals may be lower than that of the average student. Thus, we hypothesize that the academic benefit of having healthier school lunches will be largest for these students.

\footnotetext{
${ }^{6}$ The qualitative results are robust to using only core test results, or in using just the English/Language Arts exam (which is the only exam taken by students in each grade). However, the point estimates are lower in specifications that only use test results from the English/Language Arts exam. This is consistent with other recent studies that separately measure the effect of access to school breakfast on test scores in different subjects (e.g., Dotter [2014]; Imberman and Kugler [2014]).
} 
Finally, district-level demographic and socioeconomic information is available from the California Department of Education, including enrollment by race, enrollment in English learner programs (i.e., English as a second language), and the number of enrolled students who are economically disadvantaged, as defined by eligibility for free or reduced price lunches. We use this information to control for time-varying differences within schools in our main econometric model.

\section{Empirical Specification}

Our main empirical specification is a panel regression model.

$$
y_{g s t}=\beta_{0}+\delta_{H} \text { Healthy }_{s t}+\delta_{S} \text { Standard }_{s t}+X_{s t} \beta+\lambda_{g s}+\gamma_{t}+\epsilon_{g s t}
$$

The dependent variable $y_{g s t}$ is the mean STAR test score across all tests for grade $g$ in school $s$ in year $t$. The dependent variable is measured in STAR test standard deviation units.

Our independent variables of interest are whether a student test-taker is exposed to a standard or healthy outside lunch provider. Recall that a provider is classified as healthy if its HEI score is above the median score among providers. The variable Healthyst equals one if school $s$ contracts with a healthy outside lunch provider in year $t$ and zero otherwise. The variable Standard $d_{s t}$ equals one if school $s$ contracts with a standard outside lunch provider in year $t$ and zero otherwise. When both Standard $_{s t}$ and Healthy $y_{s t}$ equal zero, then the school does not contract with an outside lunch provider; the school's employ- 
ees (i.e., cafeteria workers) both prepare and serve the lunches.

The model includes school-by-grade $\left(\lambda_{g s}\right)$ and year $\left(\gamma_{t}\right)$ fixed effects. The school-by-grade fixed effects control for any characteristics in a given grade and school that are stable throughout the five-year estimation period (e.g., school catchment area characteristics, school infrastructure, STAR test differences by grade, or school staffing levels and leadership). Year fixed effects control for common state-wide factors such as state economic conditions and differences in the STAR test that vary by year throughout the panel. Most specifications of the model also include $X_{s t}$, a vector of district-level control variables that vary over time. These control variables include the racial composition of students in the district to which school $s$ belongs, the proportion of students in English learner programs, and the proportion of economically disadvantaged students. Because the decision to contract with a lunch vendor (whether healthy or standard) almost always occurs at the district level, as opposed to the individual school level, it is sufficient to control for district-level covariates that may be correlated with this decision. ${ }^{7}$

Because a contract usually covers all schools in a district, we estimate Equation (1) with standard errors clustered at the school district level. Our preferred specification uses the number of test-takers for each grade-schoolyear observation as weights in the regression. Weighting by the number of test-takers allows us to recover the relationship between the type of school lunch served and academic performance as measured by the STAR test for the

\footnotetext{
${ }^{7}$ We also experimented with controlling for similar school-level covariates that we constructed directly from the STAR data. Controlling for these covariates at the school level has little impact on the coefficient estimates, but it results in many dropped observations because of frequent missing demographic information in the STAR data.
} 
average student, rather than the average school.

The identifying assumption is that, after controlling for time-invariant school-by-grade factors, common state factors, and the vector of time-varying, school-level characteristics, a school's decision to contract with an outside vendor for school lunch provision is uncorrelated with other school-specific, time-varying factors that affect student test performance. If this is true, then we can interpret the estimate for $\delta_{H}\left(\right.$ and $\left.\delta_{S}\right)$ as the causal effect of contracting with a healthy (or standard) school lunch provider on student learning, as measured by performance on the STAR test.

\section{Results}

\subsection{Vendor Choice and Test-Taker Characteristics}

Appendix Table A2 shows mean test-taker socioeconomic and racial characteristics for schools in two different samples: the All School sample and the Contract School sample. The All School sample includes all school districts in the state of California. The Contract School sample is limited to the subset of districts that had a school lunch vendor contract for at least one year in our five-year panel. The means for each test-taker characteristic are calculated by first taking the five-year (2009-2013) district-level mean. In the All School sample, the average district mean is then calculated separately for districts that contract with a vendor (Column 1) and do not contract with a vendor (Column 2) during our panel (2009-2013). Column (3) calculates the difference in means and provides the $p$-value (in parentheses) from a test of 
the null hypothesis that the means of the two groups are equal. The means are statistically different from each other at the $5 \%$ level for five of the six characteristics. For example, districts that contract with a vendor during our sample period tend to have fewer economically disadvantaged students and a higher proportion of Asian students.

Appendix Table A2 also shows that, even among districts that contracted with a vendor at some time, those districts that contracted with a healthy vendor have different student characteristics (on average) than those districts that contracted with a standard vendor. These differences in test-taker characteristics in the two samples affect the generalizability of any association between test scores and vendor quality. Nevertheless, the differences in average characteristics between test-takers do not violate the identification assumption of Equation 1.

Table 1 shows how changes in the test-taker characteristics correlate with the timing of a vendor contract. We cannot interpret an observed correlation between vendor adoption and test score changes as a causal effect if changes in test-taker characteristics at a school can predict when a school contracts with an outside vendor. Table 1 displays the coefficient estimates from 12 different regressions using a version of Equation (1). In each of the first five columns, we use a different test-taker characteristic as the dependent variable in place of test scores. In the last column, we use the fitted values from a regression of test scores on all five test-taker characteristics (and year and school-by-grade fixed effects) as the dependent variable. These fitted values summarize all of the test-taker characteristics, weighting each characteristic in relation to its 
correlation with test scores. All regressions in Table 1 include school-by-grade fixed effects and thus test whether within-school-by-grade changes in student characteristics correlate with the time at which a school adopted an outside lunch provider.

Panel A of Table 1 estimates models using the All School sample ${ }^{8}$, while Panel B uses the Contract School sample. ${ }^{9}$ The point estimates are small in magnitude and precisely estimated. None of the estimated coefficients are statistically significant at conventional levels. The estimates in the last column of Panel A reveal that adoption of a healthy vendor correlates with a statistically insignificant 0.010 standard deviation increase in predicted test scores. The estimates for adoption of a standard vendor are also small and statistically insignificant. We interpret these results as initial evidence that changes in test-taker characteristics are uncorrelated with the timing of when a school contracts with a lunch provider. Section 5 considers several additional tests of the validity of our identifying assumption.

\subsection{Vendor Choice and Test Scores}

Table 2 shows estimation results for the effect of vendor quality on STAR scores. The first three columns estimate versions of Equation (1) on the All School sample, while the last three columns use the Contract School sample. Column (1) estimates the effect of contracting with a standard or healthy lunch vendor on test scores and includes school and year fixed effects as controls.

\footnotetext{
${ }^{8}$ This includes all elementary, middle, and high schools in California that report STAR scores.

${ }^{9}$ This comprises all schools located in districts that had a school lunch vendor contract for at least one year in our five year panel
} 
Column (2) adds school-by-grade fixed effects, while Column (3) adds the vector of student test-taker characteristics. The point estimate of the effect of having a healthy vendor on test scores, relative to no outside vendor, ranges from 0.034 to 0.036 standard deviations and is statistically significant at the $0.1 \%$ level in each of the three specifications. The estimate for a standard vendor is positive, but not statistically different from zero in any specification. The estimates for a healthy vendor from the Contract School sample are also statistically significant at the $0.1 \%$ level and are very similar to those estimated with the All School sample (ranging from 0.036 to 0.040 ). ${ }^{10}$ The estimates for the standard vendor are again positive but not statistically significant.

The fact that we observe very similar point estimates for the vendor coefficients in Columns (2) and (3) (and Columns (5) and (6)) is consistent with the conclusion from Table 1. If student characteristics were important in predicting when a school contracts with an outside vendor, then the coefficients in Table 1 would be statistically significant and the vendor estimates in Table 2 would likely differ between specifications with and without these variables.

Table 3 investigates whether the effect of contracting with a lunch provider on STAR scores is different for economically disadvantaged and economically advantaged students. Recall that economically disadvantaged students are defined by the CA Department of Education as those students who qualify for reduced price and/or free school lunch under the NSLP based on family income. We expect that disadvantaged students would be more likely to eat a school lunch than their classmates who do not qualify for reduced price or

\footnotetext{
${ }^{10}$ Our results are also qualitatively similar if we estimate Equation (1) without using student enrollment weights. These results can be found in Appendix Table A3.
} 
free school lunch. Thus, we hypothesize that the effect on test scores of eating a healthy school lunch should be greater for disadvantaged students than for students who do not qualify for reduced price or free school lunch. Table 3 shows only modest evidence in support of this hypothesis.

Table 3 again considers both the All School and Contract School samples, but limits the samples to those schools which report separate average STAR scores for both economically advantaged and economically disadvantaged students. ${ }^{11}$ Column (1) of Table 3 estimates the effect of contracting with a lunch vendor on the average test score for economically disadvantaged students. Column (2) estimates the effect on the average test scores for economically advantaged students, while Column (3) estimates the effect for all students. The point estimates for contracting with a healthy vendor are similar for both the advantaged and disadvantaged students in the All School Sample. The point estimate for contracting with a healthy vendor in the Contract Sample is about $50 \%$ larger for disadvantaged students (0.045) than for advantaged students (0.032), but this difference is not statistically significant.

There is also evidence for a positive and statistically significant effect on test scores for disadvantaged students at schools that contract with a standard lunch provider. This suggests that there could be a positive effect on test scores based purely on an increased caloric intake by disadvantaged students. For example, the outside vendor might do a better job of preparing the same meals (e.g., pizza) relative to the cafeteria workers, thereby making the school

\footnotetext{
${ }^{11}$ Due to privacy restrictions, the CA Department of Education releases the average test score (for a school-grade-year-subgroup) only if there are at least 10 students of the particular socioeconomic group who take the test. There is a $25 \%$ reduction in the size of the sample due to these sample restrictions.
} 
lunches more palatable to the students and leading to increased consumption. An alternative explanation is that even the standard vendors are marginally more healthy than the average meal prepared by the cafeteria workers, and that this difference is statistically significant when we focus on the students most likely to eat these meals. ${ }^{12}$ We attempt to tease apart these possible explanations in Section 5 by looking at the number of lunches served. Finally, recall that we code a small number of vendors with missing menu data as standard vendors. In reality, a fraction of these vendors could be healthy, in which case the standard vendor coefficient would have a modest bias in the direction of the healthy vendor coefficient.

\subsection{Robustness Checks}

Table 1 showed initial evidence that changes in test-taker characteristics are uncorrelated with the timing of when a school contracts with a lunch provider. In this section, we further test the validity of our identifying assumption that a school's decision to contract with an outside vendor for school lunch provision is uncorrelated with other school-specific, time-varying factors that affect student test performance.

Equation (2) is an event-study model that tests whether there is a correlation between test scores and contracting with a vendor in years before the vendor contract begins and in years after the vendor contract ends.

\footnotetext{
${ }^{12}$ We do not have HEI scores for the in-house lunch menus and thus cannot compare the HEI score for the typical in-house menu to that of a standard vendor.
} 
$y_{g s t}=\beta_{0}+\sum_{\tau=-4}^{4} \delta_{H}^{\tau}$ Healthy $y_{s t}^{\tau}+\sum_{\tau=-4}^{4} \delta_{S}^{\tau} \operatorname{Standard}_{s t}^{\tau}+X_{s t} \beta+\lambda_{g s}+\gamma_{t}+\epsilon_{g s t}$

Equation (2) is identical to our main estimating equation, except that we replace the single indicator variables for whether a school contracted with a

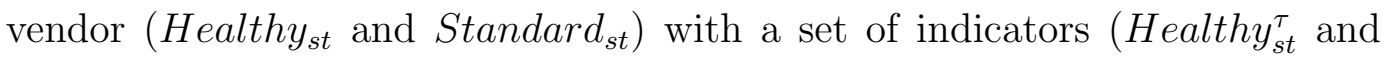
$\left.\operatorname{Standard}_{s t}^{\tau}\right)$ that also include indicators for the years before $(\tau<0)$ and after $(\tau>0)$ the school contracted with a vendor. ${ }^{13}$ The indicator variables for a year before a contract are normalized to zero when we estimate Equation (2). Thus, the estimated coefficients $\delta_{H}^{\tau}$ and $\delta_{S}^{\tau}$ are interpreted as the change in test scores for students in grade $g$, school $s$, and year $t$ relative to the year before a contract.

Figure 1 plots the estimated healthy (circles) and standard (squares) vendor event time coefficients and the $95 \%$ confidence intervals for the All School sample. The $\mathrm{x}$-axis measures event time years (i.e., $\tau$ ) and the y-axis measures test scores for all test takers. In a healthy vendor contract year, there is an increase in test scores of 0.038 standard deviations relative to the year before a contract. ${ }^{14}$ There is no evidence that increases in test scores precede contracting with a vendor, nor is there evidence for an upward pre-trend in test scores. Similarly, none of the estimated coefficients in the years after

\footnotetext{
${ }^{13}$ For example, $\tau=-4$ equals 1 if a school contracted with a vendor four years later (zero otherwise), and $\tau=4$ if a school contracted with a vendor four years earlier (zero otherwise).

${ }^{14}$ As a comparison, the estimate of the effect on test scores for the year of a healthy vendor contract from Equation (1) on the same sample is 0.034 (Table 2, Column 3).
} 
a contract ends are statistically significant. ${ }^{15}$ Finally, none of the standard vendor coefficients are statistically significant.

There are two caveats to the analysis in Figure 1. First, the event study coefficients toward the ends of our panel are imprecisely estimated because there are fewer observations to identify these coefficients. ${ }^{16}$ We address this concern by also estimating a model that pools the event time coefficients. Second, we do not know whether a school contracted with a vendor in the years before our five-year panel begins, which could attenuate our estimates if there is persistence in the test score effect after the vendor contract ends. That is, the model would be incorrectly attributing the lagged effect on test scores (from having a vendor before our panel begins) to the new vendor contract in our panel. ${ }^{17}$ We conclude that this is unlikely to be a concern because we find no evidence below that the effect on test scores persists after a contract ends.

Table 4 presents the estimation results of seven additional specifications that further test our identifying assumptions and the robustness of our main test score results. Column (1) controls for district-level school expenditures and student-teacher ratios. The expenditure and student-teacher ratio data are retained by the $\mathrm{CA}$ Department of Education and are only available at

\footnotetext{
${ }^{15}$ We also fail to reject $\mathrm{F}$-tests that all of the coefficients in the years before a contract are equal to zero, and that all of the coefficients in the years after a contract are equal to zero.

${ }^{16}$ For example, the indicator for four years before a vendor contract can equal one only if a school contracted with a vendor in the last year of our panel. By contrast, an indicator for one year after a vendor contract ends could equal one for four of the five years in our panel.

${ }^{17}$ For example, Gallagher [2014] examines the effect on the take-up of flood insurance after a community is flooded, using a model similar to Equation (2). He shows that the estimate for flood insurance take-up in the year of a flood is about $20 \%$ lower if the model fails to control for the lagged effect of a flood that occurred before the panel period.
} 
the district level. We convert the expenditure data to thousands of dollars (2013\$) per average daily student attendance. We view the expenditure and student-teacher ratio variables as proxies for whether there were additional school policy changes that occurred at the same time as the lunch vendor decisions. The estimated coefficients for healthy and standard lunch providers in Column (1) are very similar to those without the expenditure and studentteacher controls (Table 2, Column 3). Neither the expenditure nor studentteacher coefficient is statistically significant. ${ }^{18}$

Column (2) reports a specification in which we aggregate the data to district-by-year level, since the variation in vendor quality generally occurs at the district level. The estimated marginal effect of a healthy vendor on test scores is similar to that from our baseline specification. ${ }^{19}$

Column (3) estimates Equation (2) but, for statistical power, pools the event time indicators for the years before and after a vendor contract (e.g., Sojourner et al. [2014]). That is, the indicator pre-trend equals one if any of the indicators for $\tau \in[-4,-2]$ equals one, and post-trend equals one if any of the indicators for $\tau \in[1,4]$ equals one. The indicator for the year before a new vendor contract remains normalized to zero. A significant negative pre-trend coefficient would suggest that school test scores are increasing even before the introduction of a new lunch vendor. We do not find evidence of any trends before or after a school contracted with a vendor.

\footnotetext{
${ }^{18}$ Results are similar if we separately control for expenditures and student-teacher ratio.

${ }^{19}$ Note that the healthy and standard vendor variables are weighted averages of the schoolby-grade level exposure to the vendors in each year and thus take on values between 0 and 1. The average value for the healthy vendor variable (conditional on having at least one school in the district that contracted with a healthy vendor for the year) is 0.64 .
} 
Column (4) of Table 4 considers a placebo test in the spirit of Equation (2), where we incorrectly consider the year before a vendor contract as the year of a contract (e.g., Currie et al. [2010]). We define healthy placebo (standard placebo) as equal to one if the school contracts with a healthy (standard) vendor in the following year. The estimated coefficients for both vendor placebos are close to zero and not statistically different from zero after controlling for the actual vendor years. There is no evidence that test scores begin to rise in the year before a school contracts with a vendor. ${ }^{20}$

Columns (5) and (6) consider the sub-samples of schools from the Contract Sample that ever contracted with a standard or healthy vendor, respectively. ${ }^{21}$ The similarity in the coefficient estimates across the All School, Contract, and Healthy Contract samples provides further evidence that our results are not driven by differential trends in test scores among the schools that eventually contracted with a healthy vendor.

Finally, Column (7) tests whether scores increase more in the two years or more following adoption of a healthy lunch vendor. This would be the case if there were a year-to-year compounding effect of having a healthy lunch provider, such that the learning, as reflected in test scores in the first year, prepares the student to do better in the second year (over and above the effect of having a vendor in the second year). To conduct this test, we add an indicator variable to Equation (1) that equals one if a school has a healthy

\footnotetext{
${ }^{20}$ The estimated placebo coefficients are also close to zero and not statistically significant in a specification that does not condition on the actual vendor years.

${ }^{21}$ As in the contract sample, this sample excludes schools that never had an outside vendor and further restricts the sample by excluding schools whose only outside vendors have been categorized as healthy. A school that contracted with both a healthy and an unhealthy vendor within our five-year sample would be included.
} 
vendor and has had a healthy vendor for at least two consecutive years. We limit the sample to schools that only have healthy vendors and exclude the lowest level grade from these schools (e.g., we exclude grade 9 tests from high schools with grades 9-12). ${ }^{22}$ The estimate for having a vendor for two years or more is positive but imprecisely estimated.

\section{Discussion}

\subsection{Student Health}

Congress passed the Healthy, Hunger-Free Kids Act (HHFKA) in 2010 with the aim of increasing the minimum nutritional standards that school lunches must meet. For example, the number of mandated servings of fruits and vegetables increased, while at the same time restrictions were placed on the number of servings of French fries (USDA [2012]). A major goal of the law is to improve the health of school-age children via a reduction in obesity (USDA [2013]).

Previous research has shown that the source of a student's school lunch can affect obesity rates. Schanzenbach [2009] provides evidence that public school lunches have contributed to increases in childhood obesity rates. Students who are more likely to consume public school lunches, rather than other options such as bringing a brown-bag lunch, gain more weight. Currie et al. [2010] estimate that less than one academic year of exposure to fast-food restaurants

\footnotetext{
${ }^{22}$ The rationale for excluding the lowest level grade from each school is to ensure that students who continuously go to the same school would have at least two years of exposure to the vendor lunches.
} 
near schools increases obesity rates for 9 th grade students by about $5 \%$. Currie et al. [2010] and Cutler et al. [2003] both emphasize that large increases in obesity rates could occur from as few as 100 excess calories per day.

We use the same source of physical fitness information as Currie et al. [2010] to test whether exposure to healthier school lunch options decreases student obesity. The Physical Fitness Test (PFT), also called FitnessGramß, is given to students in grades 5, 7, and 9 each spring in California. The PFT is composed of six fitness areas, one of which is body composition. Schools have the option to complete the body composition portion using one of three measures: Body Mass Index (BMI), skin fold measurements or bioelectric impedance analyzer. For each of these measurements, there is a defined "healthy zone" that varies by age and gender. The data are aggregated by school and grade level and indicate the percentage of students who have a body composition measurement in the healthy fitness zone. Following Currie et al. [2010], we define overweight as the percentage of students falling outside the healthy zone.

We do not find any evidence that contracting with a healthy lunch provider reduces the percentage of overweight students. We estimate Equation (1), except that we use the percentage of students who are outside the healthy fitness zone (whom we label as "overweight") as the dependent variable and restrict the sample to grades 5, 7, and 9. ${ }^{23}$ Columns (1) and (2) of Table 5 show estimation results for all students and economically disadvantaged students, respectively. On average, $38.6 \%$ of the students (41.7\% of disadvantaged students) in our sample are overweight. All four point estimates in Columns (1)

\footnotetext{
${ }^{23}$ The Contract School sample for this regression includes 4,006 grade-year observations at 910 schools.
} 
and (2) are small and statistically insignificant. By comparison, the $95 \%$ confidence intervals for the standard vendor estimates exclude an effect size as large as that found by Currie et al. [2010] (5.2\%). A $-5.2 \%$ change in the proportion of overweight students, however, lies within the $95 \%$ confidence interval for healthy vendors.

\subsection{Number of Lunches Served}

The first provisions of the HHFKA became binding beginning with the 20122013 school year. One criticism of the law is that improving the health content of the lunches may have the unintended consequence of reducing the number of students eating school lunches (Confessore [2014]), possibly because of students' tastes. A decrease in the number of meals served to students eligible for reduced price or free lunches would be concerning because these students are considered most at risk for undernourishment and are the target population under the National School Lunch Program.

In order to estimate the impact of vendor quality on the number of lunches served in a district, we obtained NSLP data from the California Department of Education's Nutrition Services Division for the school years 2008-09 through 2012-13. The data report the average number of total NSLP lunches and the average number of free or reduced price lunches served per operating day in each school district for each month. We use the monthly averages to calculate a single operating day average for the number of lunches served and the number of free or reduced price lunches served over the course of the academic year. ${ }^{24}$

\footnotetext{
${ }^{24}$ We provide details of this calculation in the Appendix.
} 
Columns (3) and (4) of Table 5 report the impact of contracting with healthy and standard vendors on the number of daily lunches served per student. Column (3) estimates the effects on total lunches, while Column (4) estimates the effects on reduced price and/or free lunches. These regressions are run with observations at the level of district-year, rather than schoolgrade-year, because data on lunch purchases is only available aggregated at the district level. This constraint imposes minimal cost, however, because the treatment only varies at the district-year level. The dependent variable is the number of daily lunches sold per student (in Column (4), we only consider the number of reduced price and/or free lunches and the number of economically disadvantaged students). We do not find a significant effect of contracting with a healthy or standard vendor on the total number of lunches or the number of free or reduced price lunches. For example, the estimated coefficients for contracting with a healthy or a standard vendor in Column (3) are of a similar magnitude and imply a statistically insignificant reduction in the number of school lunches of approximately 10\% (the sample mean of the dependent variable is 0.45$)$.

The fact that disadvantaged students do not purchase more school lunches when the school contracts with a vendor supports the interpretation that the observed increase in test scores is due to the quality and not the quantity of school lunch meals consumed. At the same time, these findings help allay concerns that healthier lunches may actually lead to a reduction in the number of lunches served to students. 


\subsection{Policy Counterfactual}

Public school administrators interested in improving the level of student learning and increasing test scores face decisions on how best to budget limited school resources. There are many potential changes in school policy that could improve learning. For example, school administrators could hire more teachers to decrease average classroom size (Krueger [1999]), lengthen the school day (Patall et al. [2010]), increase teacher training (Angrist and Lavy [2001]), give bonus pay to teachers based on student test scores (Fryer [2011]), or increase student access to free or reduced price breakfast and lunch (Imberman and Kugler [2014]). ${ }^{25}$

Policies that direct resources toward teachers have been found to have a relatively large impact on student test scores in some settings. The Tennessee STAR experiment, which reduced average class size for primary school students by one-third and led to a 0.22 standard deviation test score increase, is a frequently cited benchmark. Nevertheless, these types of policies are often expensive and can be controversial (e.g., incentive pay). The Tennessee STAR experiment cost approximately $\$ 25$ million (2013 \$), with an implied cost of $\$ 3,009$ (2013 $\$$ ) per student placed in a smaller class. ${ }^{26}$ Jacob and Rockoff [2011] highlight both the need and opportunity for cost-effective policies; lowercost policies with modest effects on student test scores may generate a better return than costly policies with larger absolute effects.

We take advantage of contract-specific winner and loser bid information

\footnotetext{
${ }^{25}$ This list highlights only a handful of policies and is not meant to be exhaustive.

${ }^{26}$ The original cost estimates reported by Krueger [1999] are adjusted to $2013 \$$ using the Consumer Price Index (CPI).
} 
submitted to the CA Department of Education to calculate the cost differences between healthy and standard lunch providers. The average price per lunch in healthy meal vendor contracts is $\$ 2.45$. This is close to the National School Lunch Program reimbursement rate of $\$ 2.93$ per free lunch, suggesting that healthy school meal vendors do not cost dramatically more than in-house preparation. To compute a plausible upper bound on the cost of increasing test scores via healthy school meal vendors, we assume that healthy school meal vendors cost $25 \%$ more than in-house preparation. This assumption implies that the average school makes a net profit of $33 \%$ on its school meal operations when reimbursed by the NSLP. A profit margin of this size or larger is unlikely because the NSLP specifically forbids the use of these revenues to fund non-food service operations (GPO, 7 CFR, Section 210.14(a)).

The average healthy vendor meal contract is $\$ 400(2013 \$)$ per test-taker per school year. The California school year is 180 school days; on average, a healthy school meal contract costs about $\$ 2.22$ per test-taker day. We assume that the contract is $25 \%$ more expensive than in-house meal preparation, implying a difference of $\$ 80$ per test-taker per school year. To compare cost effectiveness we consider the dollar cost per 0.1 standard deviations of test score gains; this normalization does not imply that we can achieve a full 0.1 standard deviation increase with any given policy, including healthy vendor contracts. Using a cost difference of $\$ 80$ per test-taker per school year and an estimated effect of 0.036 standard deviations (Column (3) of Table 2), we find that it would cost about $\$ 222$ per year to raise a student's test score by 0.1 standard deviations through switching from in-house preparation to a healthy 
lunch provider. In contrast, it cost $\$ 1,368$ per year to raise a student's test score by 0.1 standard deviations in the Tennessee STAR experiment. Thus, even the upper bound on the cost of raising test scores by 0.1 standard deviations through healthy meals is many times lower than the comparable observed cost in Tennessee STAR.

\section{Conclusion}

We exploit variation in the nutritional quality of school meals resulting from changes in meal providers to estimate the effect of nutritional quality on the academic performance of primary and secondary school students across the state of California. Using differences-in-differences type specifications, we find that switching to a healthy meal vendor is associated with a 0.036 standard deviation increase in test scores. While this effect is small in magnitude, the relatively low cost of healthy vendors relative to in-house meal preparation makes this a very cost-effective way to raise test scores.

We conduct a variety of robustness checks, including placebo tests and an event study specification, to provide evidence that the timing of changes in meal providers is uncorrelated with omitted variables that could be driving changes in test scores. There is also no evidence that the introduction of healthier school lunches led to a change in the number of school lunches consumed. This supports our view that the observed correlation between healthier school lunches and test scores is due to the nutritional quality of the meals rather than the quantity of calories consumed. An analysis of the effects of 
healthy meal vendors on the percentage of students who are overweight finds no effect, but it is possible that these effects could occur on a longer time horizon.

\section{References}

Harold Alderman, Jere R. Behrman, and John Hoddinott. Economic and nutritional analyses offer substantial synergies for understanding human nutrition. Journal of Nutrition, 137(3):537-544, 2007.

Joshua Angrist and Victor Lavy. Does teacher training affect pupil learning? evidence from matched comparisons in jerusalem public schools. Journal of Labor Economics, 19(2):343-369, 2001.

Michele Belot and Jonathan James. Healthy school meals and educational outcomes. Journal of Health Economics, 30:489-504, 2011.

Janet Bryan, Saskia Osendarp, Donna Hughes, Eva Calvaresi, Katrine Baghurst, and Jan-Willem van Klinken. Nutrients for cognitive development in school-aged children. Nutrition Reviews, 62(8):295-306, 2004.

California Department of Education. California standardized testing and reporting, post-test guide technical information for star district and test site coordinators and research specialists. Technical report, 2011.

Nicholas Confessore. How school lunch became the latest political battleground. The New York Times Magazine, 2014. URL http://www.nytimes.com/2014/10/12/magazine/ how-school-lunch-became-the-latest-political-battleground.html? _r $=0$.

Janet Currie, Stefano DellaVigna, Enrico Moretti, and Vikram Pathania. The effect of fast food restaurants on obesity and weight gain. American Economic Journal: Economic Policy, 2:32-63, August 2010.

David M. Cutler, Edward L. Glaeser, and Jesse M. Shapiro. Why have americans become more obese? Journal of Economic Perspectives, 17:93-118, 2003. 
Dallas Dotter. Breakfast at the desk: The impact of universal breakfast programs on academic performance. Association for Public Policy Analysis and Management Online Paper Collection, 2014.

Temitope O Erinosho, Sarah C Ball, Phillip P Hanson, Amber E Vaughn, and Dianne Stanton Ward. Assessing foods offered to children at child-care centers using the healthy eating index-2005. J Acad Nutr Diet, 113(8):1084-9, Aug 2013. doi: 10.1016/j.jand.2013.04.026.

David N. Figlio and Joshua Winicki. Food for thought: The effects of school accountability plans on school nutrition. Journal of Public Economics, 89:381-394, 2005 .

David E. Frisvold. Nutrition and cognitive achievement: An evaluation of the school breakfast program. Journal of Public Economics, 124:91-104, 2015.

Roland G. Fryer. Teacher incentives and student achievement: Evidence from new york city public schools, March 2011.

Justin Gallagher. Learning about an infrequent event: Evidence from flood insurance takeup in the us. American Economic Journal: Applied Economics, 6: 206-233, 2014.

Paul Glewwe and Edward A. Miguel. The impact of child health and nutrition on education in less developed countries. Handbook of Development Economics, 4: 3561-3606, 2008.

Fernando Gomez-Pinilla. Brain foods: the effects of nutrients on brain function. Nature Reviews Neuroscience, 9:568-578, July 2008.

US GPO. eCFR - Code of Federal Regulations. URL http://www.ecfr.gov/ cgi-bin/text-idx?rgn=div5\&node=7:4.1.1.1.1.

Patricia M. Guenther, Kellie O. Casavale, Sharon I. Kirkpatrick, Jill Reedy, Hazel A. B. Hiza, Kevin J. Kuczynski, Lisa L. Kahle, and Susan M. Krebs-Smith. Diet quality of americans in 2001-02 and 2007-08 as measured by the healthy eating index-2010. Technical report, US Department of Agriculture, Economic Research Service, April 2013a.

Patricia M. Guenther, Kellie O. Casavale, Jill Reedy, Sharon I. Kirkpatrick, Hazel A.B. Hiza, Kevin J. Kuczynski, Lisa L. Kahle, and Susan M. Krebs-Smith. Update of the healthy eating index: Hei-2010. Journal of the Academy of Nutrition and Dietetics, 113:569-580, 2013b.

Peter Hinrichs. The effects of the national school lunch program on education and health. Journal of Policy Analysis and Management, 29(3):479-505, 2010. 
Kristen M. Hurley, Sarah E. Oberlander, Brian C. Merry, Margaret M. Wrobleski, Ann C. Klassen, and Maureen M. Black. The healthy eating index and youth healthy eating index are unique, nonredundant measures of diet quality among low-income, african american adolescents. Journal of Nutrition, 139(2):359-364, 2009 .

Scott A. Imberman and Adriana D. Kugler. The effect of providing breakfast on student performance. Journal of Policy Analysis and Management, 33:669-699, 2014 .

Brian A. Jacob and Jonah E. Rockoff. Organizing schools to improve student achievement: Start times, grade configurations, and teacher assignments. Brookings Institution, September 2011.

Alan B. Krueger. Experimental estimates of education production functions. The Quarterly Journal of Economics, 114(2):497-532, 1999.

Jacob Leos-Urbel, Amy Ellen Schwartz, Meryle Weinstein, and Sean Corcoran. Not just for poor kids: The impact of universal free school breakfast on meal participation and student outcomes. Economics of Education Review, 36:88-107, 2013.

Yannis Manios, Georgia Kourlaba, Katerina Kondaki, Evangelia Grammatikaki, Manolis Birbilis, Evdokia Oikonomou, and Eleytheria Roma-Giannikou. Diet quality of preschoolers in greece based on the healthy eating index: The genesis study. American Dietetic Association, 109:616-623, 2009.

Arindam Nandi, Jere Behrman, Sonia Bhalotra, Anil Deolalikar, and Ramanan Laxminarayan. The human capital and productivity benefits of early childhood nutritional interventions. Disease Control Priorities, 2015. URL http://dcp-3.org/chapter/1938/ human-capital-and-productivity-benefits-early-childhood-nutritional-interventions.

Erika A. Patall, Harris Cooper, and Ashley Batts Allen. Extending the school day or school year: A systemic review of research (1985-2009). Review of Educational Research, 80(3), September 2010.

Jill Reedy, Susan M. Krebs-Smith, and Claire Bosire. Evaluating the food envirionment, application of the healthy eating index-2005. American Journal of Preventive Medicine, 38(5):465-471, 2010.

Diane Whitmore Schanzenbach. Do school lunches contribute to childhood obesity? Journal of Human Resources, 44(3):684-709, 2009. 
Diane Whitmore Schanzenbach and Mary Zaki. Expanding the school breakfast program: Impacts on children's consumption, nutrition and health. National Bureau of Economic Research Working Paper 20308, July 2014.

Aaron J. Sojourner, Elton Mykerezi, and Kristine L. West. Teacher pay reform and productivity: Panel data evidence from adoptions of q-comp in minnesota. Journal of Human Resources, 49(4), 2014.

Annik Sorhaindo and Leon Feinstein. What is the relationship between child nutrition and school outcomes. Technical report, Centre for Research on the Wider Benefits of Learning, June 2006.

USDA. Strategic Plan for FY 2005-2010, June 2006. URL http://www . ocfo. usda. gov/usdasp/sp2005/sp2005.pdf.

USDA. Nutritional standards in the national school lunch and school breakfast programs, January 262012.

USDA. USDA Proposes Standards to Provide Healthy Food Options in Schools, February 2013. URL http://www.fns.usda.gov/school-meals/ healthy-hunger-free-kids-act.

USDA. Healthy eating index, 2016. URL http://www.cnpp.usda.gov/ healthyeatingindex.

Richard Volpe and Abigail Okrent. Assessing the healthfulness of consumers' grocery purchases. Technical Report EIB-102, US Department of Agriculture, Center for Nutrition Policy and Promotion, November 2012. 


\section{Figures and Tables}

Figure 1: The Effect of Healthy and Standard Vendors on Test Scores

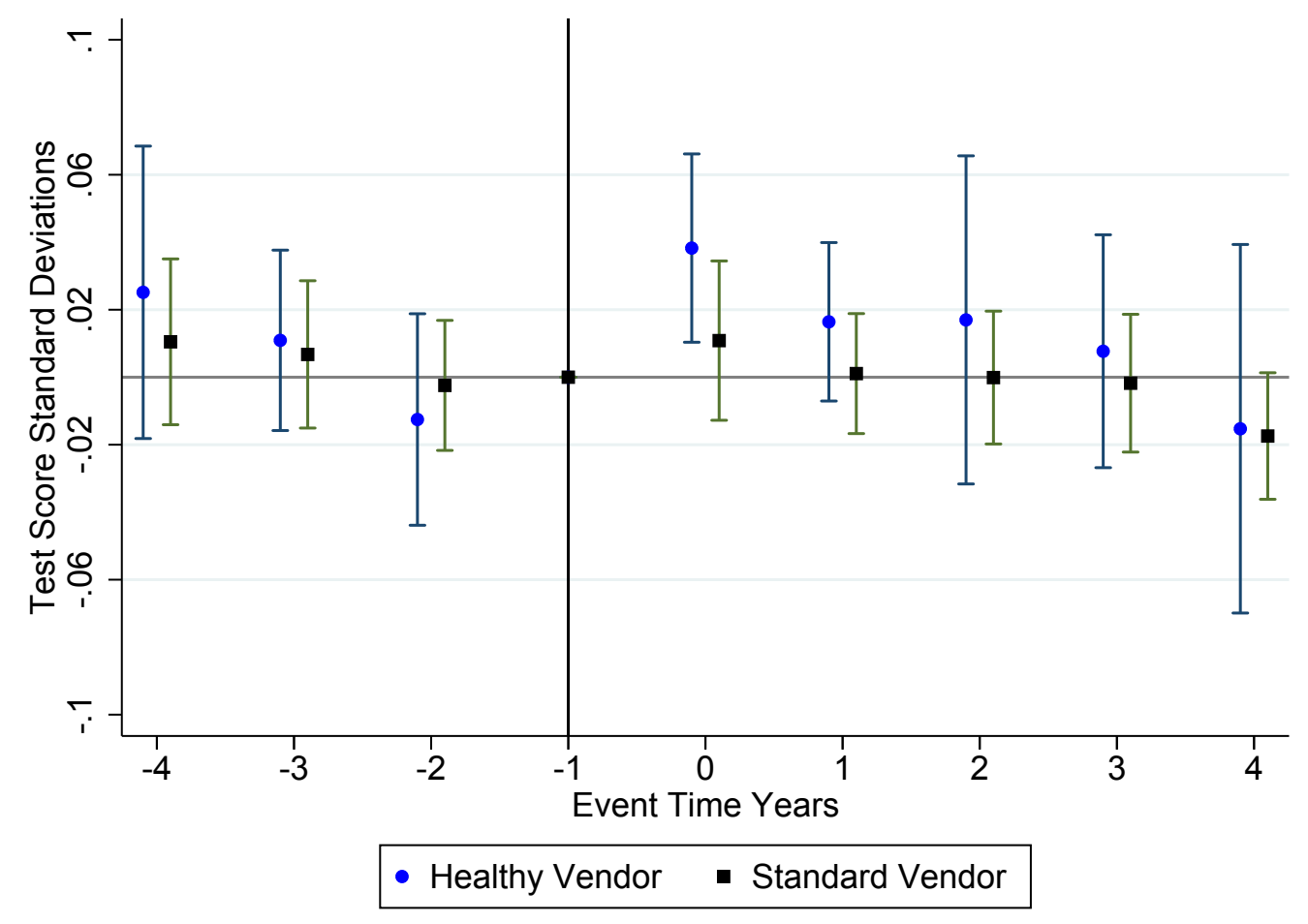

Notes: This figure depicts point estimates for treatment leads and lags with their corresponding 95\% confidence intervals. The point estimates come from a weighted regression of Equation 2 using the number of test-takers per observation as weights. The regression includes the same control variables as Table 2, Column (3). Standard errors are clustered at the school district level. 
Table 1: The Correlation between Test-Taker Covariates and the Timing of School Lunch Vendor Contracts

\begin{tabular}{|c|c|c|c|c|c|c|}
\hline Dependent variable: & $\begin{array}{c}\text { (1) } \\
\text { White }\end{array}$ & $\begin{array}{c}(2) \\
\text { Asian }\end{array}$ & $\begin{array}{c}\text { (3) } \\
\text { Hispanic }\end{array}$ & $\begin{array}{c}(4) \\
\text { Disadvantaged }\end{array}$ & $\begin{array}{c}\text { (5) } \\
\text { English } \\
\text { Learner }\end{array}$ & $\begin{array}{c}(6) \\
\text { Predicted } \\
\text { Test Score }\end{array}$ \\
\hline \multicolumn{7}{|c|}{ Panel A. All School Sample } \\
\hline Healthy Vendor & $\begin{array}{c}0.003 \\
(0.005)\end{array}$ & $\begin{array}{l}-0.007 \\
(0.004)\end{array}$ & $\begin{array}{c}0.004 \\
(0.004)\end{array}$ & $\begin{array}{l}-0.014 \\
(0.018)\end{array}$ & $\begin{array}{l}-0.016 \\
(0.020)\end{array}$ & $\begin{array}{c}0.010 \\
(0.011)\end{array}$ \\
\hline Standard Vendor & $\begin{array}{l}-0.003 \\
(0.003)\end{array}$ & $\begin{array}{c}0.002 \\
(0.003)\end{array}$ & $\begin{array}{c}0.002 \\
(0.003)\end{array}$ & $\begin{array}{c}0.013 \\
(0.017)\end{array}$ & $\begin{array}{l}-0.006 \\
(0.010)\end{array}$ & $\begin{array}{c}-0.001 \\
(0.015)\end{array}$ \\
\hline $\mathrm{N}$ & 178,094 & 178,094 & 178,094 & 178,094 & 174,770 & 174,770 \\
\hline
\end{tabular}

Panel B. Contract School Sample

\begin{tabular}{lcccccc}
\hline Healthy Vendor & 0.000 & -0.007 & 0.006 & -0.035 & -0.013 & 0.022 \\
& $(0.007)$ & $(0.004)$ & $(0.005)$ & $(0.020)$ & $(0.016)$ & $(0.013)$ \\
Standard Vendor & & & & & & \\
& -0.004 & 0.003 & 0.003 & -0.009 & -0.004 & 0.012 \\
& $(0.004)$ & $(0.004)$ & $(0.003)$ & $(0.011)$ & $(0.006)$ & $(0.011)$ \\
$\mathrm{N}$ & & & & & & \\
\hline \hline
\end{tabular}

Notes: Each column represents a separate weighted regression with weights equal to the number of test takers per observation. Observations are at the school-grade-year level. Standard errors clustered at the school district level appear in parentheses. All regressions include year and school-by-grade fixed effects. The contract school sample is the subset of schools that contract with a vendor at some point during our sample. ${ }^{*} \mathrm{p}<0.05,{ }^{* *} \mathrm{p}<0.01,{ }^{* * *} \mathrm{p}<$ 0.001 
Table 2: The Effect of Vendor Choice on Standardized Test Scores

\begin{tabular}{|c|c|c|c|c|c|c|}
\hline \multirow{3}{*}{$\begin{array}{l}\text { Dependent variable: } \\
\text { Sample: }\end{array}$} & \multicolumn{6}{|c|}{ Standardized Test Score } \\
\hline & \multicolumn{3}{|c|}{ All Schools } & \multicolumn{3}{|c|}{ Contract Schools } \\
\hline & $(1)$ & $(2)$ & (3) & $(4)$ & $(5)$ & $(6)$ \\
\hline Healthy Vendor & $\begin{array}{c}0.034 * * * \\
(0.008)\end{array}$ & $\begin{array}{c}0.036 * * * \\
(0.009)\end{array}$ & $\begin{array}{c}0.036 * * * \\
(0.009)\end{array}$ & $\begin{array}{c}0.038 * * * \\
(0.008)\end{array}$ & $\begin{array}{c}0.040 * * * \\
(0.009)\end{array}$ & $\begin{array}{c}0.036 * * * \\
(0.008)\end{array}$ \\
\hline Standard Vendor & $\begin{array}{c}0.009 \\
(0.010)\end{array}$ & $\begin{array}{c}0.008 \\
(0.012)\end{array}$ & $\begin{array}{c}0.007 \\
(0.011)\end{array}$ & $\begin{array}{c}0.013 \\
(0.009)\end{array}$ & $\begin{array}{c}0.013 \\
(0.010)\end{array}$ & $\begin{array}{c}0.012 \\
(0.010)\end{array}$ \\
\hline $\begin{array}{l}\text { School-by-grade FEs } \\
\text { Covariates included }\end{array}$ & & $X$ & $\begin{array}{l}X \\
X\end{array}$ & & $\mathrm{X}$ & $\begin{array}{l}X \\
X\end{array}$ \\
\hline $\mathrm{R}^{2}$ & 0.714 & 0.930 & 0.930 & 0.700 & 0.922 & 0.922 \\
\hline $\mathrm{N}$ & 174,818 & 174,818 & 174,818 & 22,162 & 22,162 & 22,162 \\
\hline Schools & 9,719 & 9,719 & 9,719 & 1,189 & 1,189 & 1,189 \\
\hline $\begin{array}{l}\text { Notes: Each column repre } \\
\text { All regressions are estima } \\
\text { school-grade-year level. } \mathrm{S} \\
\text { fixed effects. Regressions } \\
\text { school sample is the subs } \\
* * * \mathrm{p}<0.001\end{array}$ & $\begin{array}{l}\text { Darate weight } \\
\text { ommon samp } \\
\text { rors clustere } \\
\text { de school fix } \\
\text { ols that contr }\end{array}$ & $\begin{array}{l}\text { egression w } \\
\text { hat excludes } \\
\text { the school } \\
\text { fffects unless } \\
\text { with a vend }\end{array}$ & $\begin{array}{l}\text { weights equa } \\
\text { servations w } \\
\text { ict level app } \\
\text { hool-by-grad } \\
\text { t some point }\end{array}$ & $\begin{array}{l}\text { the number } \\
\text { missing cov } \\
\text { in parenthes } \\
\text { ixed effects } \\
\text { Iring our san }\end{array}$ & $\begin{array}{l}\text { test takers } \mathrm{p} \\
\text { tes. Observa } \\
\text { All regressio } \\
\text { pecified. Th } \\
* \mathrm{p}<0.0\end{array}$ & $\begin{array}{l}\text { bservation. } \\
\text { s are at the } \\
\text { nclude year } \\
\text { ntract } \\
\mathrm{p}<0.01 \text {, }\end{array}$ \\
\hline
\end{tabular}


Table 3: The Effect of Vendor Choice on Standardized Test Scores by Socioeconomic Status

\begin{tabular}{|c|c|c|c|c|c|c|}
\hline \multirow{3}{*}{$\begin{array}{l}\text { Dependent variable: } \\
\text { Sample: }\end{array}$} & \multicolumn{6}{|c|}{ Standardized Test Score } \\
\hline & \multicolumn{3}{|c|}{ All Schools } & \multicolumn{3}{|c|}{ Contract Schools } \\
\hline & (1) & (2) & (3) & (4) & (5) & (6) \\
\hline Subgroup: & Disadvantaged & Advantaged & All & Disadvantaged & Advantaged & All \\
\hline Healthy Vendor & $\begin{array}{l}0.034^{*} \\
(0.016)\end{array}$ & $\begin{array}{l}0.032 * \\
(0.016)\end{array}$ & $\begin{array}{l}0.033 * * \\
(0.013)\end{array}$ & $\begin{array}{l}0.045^{*} \\
(0.019)\end{array}$ & $\begin{array}{l}0.032^{*} \\
(0.016)\end{array}$ & $\begin{array}{l}0.037 * * \\
(0.013)\end{array}$ \\
\hline Standard Vendor & $\begin{array}{l}0.029^{*} \\
(0.013)\end{array}$ & $\begin{array}{c}0.010 \\
(0.016) \\
\end{array}$ & $\begin{array}{c}0.014 \\
(0.013) \\
\end{array}$ & $\begin{array}{c}0.033 * * \\
(0.011)\end{array}$ & $\begin{array}{c}0.019 \\
(0.014) \\
\end{array}$ & $\begin{array}{c}0.020 \\
(0.011) \\
\end{array}$ \\
\hline $\mathrm{R}^{2}$ & 0.897 & 0.906 & 0.928 & 0.880 & 0.902 & 0.919 \\
\hline $\mathrm{N}$ & 103,432 & 103,432 & 103,432 & 13,263 & 13,263 & 13,263 \\
\hline Schools & 7,607 & 7,607 & 7,607 & 940 & 940 & 940 \\
\hline
\end{tabular}

Notes: Each column represents a separate weighted regression with weights equal to the number of test takers in the subgroup indicated by the column name. All regressions are estimated on a common sample that excludes observations with missing test score data for any of the indicated subgroups. Observations are at the school-grade-year level. Standard errors clustered at the school district level appear in parentheses. All regressions include year and school-by-grade fixed effects and district-level demographic covariates. ${ }^{*} \mathrm{p}<0.05,{ }^{* *} \mathrm{p}<0.01,{ }^{* * *} \mathrm{p}<0.001$ 
Table 4: The Effect of Vendor Choice on Standardized Test Scores:

\section{Robustness Checks}

\begin{tabular}{|c|c|c|c|c|c|c|c|}
\hline \multirow{3}{*}{$\begin{array}{l}\text { Dependent Variable: } \\
\text { Model: }\end{array}$} & \multicolumn{7}{|c|}{ Standardized Test Score } \\
\hline & (1) & (2) & (3) & (4) & (5) & (6) & (7) \\
\hline & $\begin{array}{l}\text { Control for } \\
\text { Expenditures, } \\
\text { No. teachers }\end{array}$ & $\begin{array}{l}\text { District- } \\
\text { level } \\
\text { Regression }\end{array}$ & Trends & Placebo & $\begin{array}{l}\text { Standard } \\
\text { Only }\end{array}$ & $\begin{array}{c}\text { Healthy } \\
\text { Only }\end{array}$ & Accumulative \\
\hline Healthy Vendor & $\begin{array}{c}0.033 * * * \\
(0.009)\end{array}$ & $\begin{array}{c}0.046 * * * \\
(0.012)\end{array}$ & $\begin{array}{c}0.032 * * * \\
(0.009)\end{array}$ & $\begin{array}{c}0.037 * * * \\
(0.011)\end{array}$ & $\begin{array}{c}0.038 * * * \\
(0.011)\end{array}$ & $\begin{array}{c}0.029 * * \\
(0.009)\end{array}$ & $\begin{array}{c}0.037 \\
(0.020)\end{array}$ \\
\hline Standard Vendor & $\begin{array}{c}0.007 \\
(0.012)\end{array}$ & $\begin{array}{c}0.005 \\
(0.014)\end{array}$ & $\begin{array}{c}0.012 \\
(0.010)\end{array}$ & $\begin{array}{c}0.008 \\
(0.011)\end{array}$ & $\begin{array}{c}0.015 \\
(0.010)\end{array}$ & $\begin{array}{c}-0.004 \\
(0.019)\end{array}$ & \\
\hline Expenditures & $\begin{array}{c}0.001 \\
(0.001)\end{array}$ & & & & & & \\
\hline Student-Teacher Ratio & $\begin{array}{c}-0.001 \\
(0.001)\end{array}$ & & & & & & \\
\hline Pre-trend Healthy Vendor & & & $\begin{array}{l}-0.009 \\
(0.008)\end{array}$ & & & & \\
\hline Pre-trend Standard Vendor & & & $\begin{array}{c}0.009 \\
(0.009)\end{array}$ & & & & \\
\hline Post-trend Healthy Vendor & & & $\begin{array}{l}-0.009 \\
(0.016)\end{array}$ & & & & \\
\hline Post-trend Standard Vendor & & & $\begin{array}{l}-0.009 \\
(0.008)\end{array}$ & & & & \\
\hline Healthy Vendor Placebo & & & & $\begin{array}{c}0.005 \\
(0.014)\end{array}$ & & & \\
\hline Standard Vendor Placebo & & & & $\begin{array}{c}0.010 \\
(0.007)\end{array}$ & & & \\
\hline Healthy Vendor 2+ Years & & & & & & & $\begin{array}{c}0.046 \\
(0.052)\end{array}$ \\
\hline$\overline{\mathrm{R}^{2}}$ & 0.930 & 0.985 & 0.930 & 0.930 & 0.925 & 0.908 & 0.926 \\
\hline $\mathrm{N}$ & 168,377 & 4,057 & 174,818 & 174,818 & 18,696 & 7,078 & 3,470 \\
\hline Schools/Districts & 9,312 & 908 & 9,719 & 9,719 & 985 & 386 & 233 \\
\hline
\end{tabular}


Table 5: The Effect of Vendor Choice on Percent of Overweight Students and Number of School Lunches Sold

\begin{tabular}{l|cccccc}
\hline \hline \multirow{2}{*}{ Dependent variable: } & \multicolumn{2}{c}{$\%$ Overweight } & & \multicolumn{2}{c}{ Number Lunches Sold } \\
\cline { 2 - 3 } \cline { 5 - 6 } Subgroup: & $(1)$ & All & Disadvantaged & & All & Disadvantaged \\
\hline Healthy Vendor & -0.51 & 0.10 & & -0.050 & -0.075 \\
& $(0.85)$ & $(1.44)$ & & $(0.038)$ & $(0.100)$ \\
& & & & & \\
Standard Vendor & -0.51 & -0.20 & & -0.042 & -0.048 \\
& $(0.52)$ & $(0.88)$ & & $(0.028)$ & $(0.069)$ \\
\hline Dependent variable mean & 38.58 & 41.67 & & 0.447 & 0.418 \\
$\mathrm{R}^{2}$ & 0.831 & 0.764 & & 0.760 & 0.721 \\
$\mathrm{~N}$ & 43,648 & 18,105 & & 2,778 & 2,744 \\
Schools/Districts & 8,724 & 8,724 & & 785 & 785 \\
\hline \hline
\end{tabular}

Notes: Each column represents a separate weighted regression. The dependent variable in columns (1) and (2) is the percentage of students who are overweight. Observations are at the school-grade-year level and the weights are equal to the number of physical fitness test takers. The dependent variable in columns (3) and (4) is the number of school lunches sold. Observations are at the school district-year level and weights are the total student enrollment in the district. The first two regressions include school-by-grade fixed effects, while the latter two include district fixed effects. All regressions include year fixed effects and district-level covariates. Standard errors clustered at the school district level appear in parentheses. ${ }^{*} \mathrm{p}<0.05,{ }^{* *} \mathrm{p}<0.01,{ }^{* * *} \mathrm{p}<0.001$ 


\section{Appendix}

\subsection{Calculation of vendor HEI scores}

Nutritionists at the Berkeley Nutrition Policy Institute conducted an analysis of menus for those vendors for whom this information was available. A copy of the complete report can be found here: http://faculty.weatherhead. case.edu/jpg75/pdfs/Nutrition-Policy-Institute-July-2016.pdf The menus were scored using the Healthy Eating Index (HEI). The process to calculate the HEI for each vendor was the following:

1. Nutrition information was gathered from vendors. This process included obtaining the full menu of offerings and nutritional information by contacting vendors. When this information was not available, sample menus from client school districts (with or without nutritional information) were used.

2. In order to calculate HEI, it was necessary to match foods listed in vendor menus to USDA food codes.

(a) For vendors with nutritional information available, vendor foods were matched to USDA foods using the What's in the Foods You Eat online search tool

- Foods were first matched by names. Then, these matches were analyzed based on calories and fat content to determine how many USDA units corresponded to a vendor's portion.

- Units were calculated so that calories, total fat, and saturated fat matched within $20 \%$ difference.

- Entrees, meat/meat alternatives, and whole grain items were also matched by protein and fiber.

- A coding system was created to denote the quality of the match.

(b) For vendors without nutritional information, the number of total calories and other nutrients had to be imputed to determine the number of USDA units corresponding to a vendor's portion. In these cases, a number of methods were tested, which included using the average calories for other vendors and USDA defaults (e.g., the necessary amounts to meet USDA guidelines)

(c) USDA HEI SAS macros were used to determine HEI scores 
3. A supplemental scoring system was created to include additional food categories commonly found in school lunch menus. This method was reviewed by five nutrition experts.

4. The HEI and supplemental scores were combined to calculate the total scores.

\subsection{Calculation of average school lunches served}

National School Lunch Program (NSLP) data were obtained from the California Department of Education's Nutrition Services Division for the school years 2008-2009 through 2012-2013. The data report the average number of NSLP lunches served per operating day in each school district. Averages are calculated monthly, so, in order to obtain an annual measure for the average number of lunches served per day, we multiply the monthly averages by the number of operating days in each month and sum the monthly totals. The months of June and July are excluded from the total because these months may correspond to summer lunch programs that are managed separately. The annual total is divided by the total number of operating days in the year, again excluding June and July, to calculate an annual average of lunches served per day. Lastly, we divide the number of lunches served per day by the total enrollment in the school district to eliminate changes in lunches served that are due only to changes in the number of enrolled students. Because we are interested in separately estimating the effect on economically disadvantaged students, we calculate averages for both total lunches served and free lunches. A student is eligible for a free school lunch if his family's income is less than $130 \%$ of the poverty level, and a reduced price lunch if her family's income is between $130 \%$ and $185 \%$ of the poverty level. The CA Department of Education refers to these students as "economically disadvantaged". 


\section{Table A1: Vendor Healthy Eating Index (HEI) Scores by School Lunch Market Share}

\begin{tabular}{|c|c|c|c|c|c|}
\hline Vendor Name & $\begin{array}{c}(1) \\
\text { Percent of Students } \\
\text { Served } \\
\end{array}$ & $\begin{array}{c}(2) \\
\text { HEI } \\
\text { Score } \\
\end{array}$ & $\begin{array}{c}(3) \\
\text { Healthy } \\
\end{array}$ & $\begin{array}{c}(4) \\
\text { SFA } \\
\text { Contracts } \\
\end{array}$ & $\begin{array}{c}5) \\
\text { Only SFA } \\
\text { Contracts } \\
\end{array}$ \\
\hline Sodexo & 50.66 & 59.9 & $\mathrm{~N}$ & $\mathrm{~N}$ & $\mathrm{~N}$ \\
\hline Compass & 15.67 & 45.6 & $\mathrm{~N}$ & $\mathrm{~N}$ & $\mathrm{~N}$ \\
\hline CSU Dominguez Hills & 10.28 & - & $\mathrm{N}$ & $\mathrm{N}$ & $\mathrm{N}$ \\
\hline Preferred Meals & 9.51 & 71.4 & Y & $\mathrm{N}$ & $\mathrm{N}$ \\
\hline Aramark & 3.32 & 64.7 & $\mathrm{Y}$ & $\mathrm{N}$ & $\mathrm{N}$ \\
\hline Revolution Foods & 2.47 & 92.3 & $\mathrm{Y}$ & $\mathrm{Y}$ & $\mathrm{N}$ \\
\hline Royal Dining & 2.41 & 75 & $\mathrm{Y}$ & Y & $\mathrm{N}$ \\
\hline Choicelunch & 1.22 & - & $\mathrm{N}$ & $\mathrm{N}$ & $\mathrm{N}$ \\
\hline The Lunchmaster & 1.13 & - & $\mathrm{N}$ & $\mathrm{N}$ & $\mathrm{N}$ \\
\hline School Nutrition Plus & 0.86 & 67.8 & $\mathrm{Y}$ & $\mathrm{N}$ & $\mathrm{N}$ \\
\hline Kid Chow & 0.42 & 26.8 & $\mathrm{~N}$ & $\mathrm{~N}$ & $\mathrm{~N}$ \\
\hline Morrison Management Specialists & 0.32 & - & $\mathrm{N}$ & $\mathrm{N}$ & $\mathrm{N}$ \\
\hline Bellflower Unified School District & 0.29 & 69.1 & $\mathrm{Y}$ & $\mathrm{Y}$ & $\mathrm{Y}$ \\
\hline CSU Chico & 0.24 & 51.9 & $\mathrm{~N}$ & $\mathrm{~N}$ & $\mathrm{~N}$ \\
\hline Unified Nutrimeals & 0.16 & - & $\mathrm{N}$ & $\mathrm{N}$ & $\mathrm{N}$ \\
\hline Flour Creations & 0.13 & - & $\mathrm{N}$ & $\mathrm{N}$ & $\mathrm{N}$ \\
\hline Feed You Well & 0.13 & - & $\mathrm{N}$ & $\mathrm{N}$ & $\mathrm{N}$ \\
\hline Fresno County EOC & 0.09 & 43.2 & $\mathrm{~N}$ & Y & $\mathrm{N}$ \\
\hline Preferred Choice & 0.09 & 70 & $\mathrm{Y}$ & $\mathrm{N}$ & $\mathrm{N}$ \\
\hline La Luna On The Go & 0.09 & - & $\mathrm{N}$ & $\mathrm{N}$ & $\mathrm{N}$ \\
\hline Santa Clarita Food Services Agency & 0.07 & 55.5 & $\mathrm{~N}$ & $\mathrm{~N}$ & $\mathrm{~N}$ \\
\hline Oceanside Unified School District / Lighthouse Foods & 0.07 & - & $\mathrm{N}$ & $\mathrm{Y}$ & $\mathrm{Y}$ \\
\hline Dulan's Catering & 0.06 & - & $\mathrm{N}$ & $\mathrm{N}$ & $\mathrm{N}$ \\
\hline Arguello Catering & 0.05 & - & $\mathrm{N}$ & $\mathrm{N}$ & $\mathrm{N}$ \\
\hline The Food Lady & 0.04 & - & $\mathrm{N}$ & $\mathrm{N}$ & $\mathrm{N}$ \\
\hline Blue Lake Rancheria & 0.03 & - & $\mathrm{N}$ & $\mathrm{N}$ & $\mathrm{N}$ \\
\hline Banyan Catering & 0.03 & - & $\mathrm{N}$ & $\mathrm{N}$ & $\mathrm{N}$ \\
\hline Fieldbrook Family Market & 0.02 & 39.7 & $\mathrm{~N}$ & $\mathrm{~N}$ & $\mathrm{~N}$ \\
\hline Good Day Cafe - San Lorenzo Unified School District & 0.02 & - & $\mathrm{N}$ & $\mathrm{Y}$ & $\mathrm{Y}$ \\
\hline Food Management Associates & 0.02 & - & $\mathrm{N}$ & $\mathrm{N}$ & $\mathrm{N}$ \\
\hline Brown Bag Naturals & 0.02 & - & $\mathrm{N}$ & $\mathrm{N}$ & $\mathrm{N}$ \\
\hline San Bernardino School District & 0.01 & - & $\mathrm{N}$ & $\mathrm{Y}$ & $\mathrm{Y}$ \\
\hline Progressive Catering & 0.01 & - & $\mathrm{N}$ & $\mathrm{N}$ & $\mathrm{N}$ \\
\hline James Aldrege Foundation & 0.01 & - & $\mathrm{N}$ & $\mathrm{N}$ & $\mathrm{N}$ \\
\hline Aqua Terra Culinary & 0.01 & - & $\mathrm{N}$ & $\mathrm{N}$ & $\mathrm{N}$ \\
\hline Trinidad Rancheria & 0.01 & - & $\mathrm{N}$ & $\mathrm{N}$ & $\mathrm{N}$ \\
\hline Freshlunches & 0.01 & - & $\mathrm{N}$ & $\mathrm{N}$ & $\mathrm{N}$ \\
\hline Food 4 Thought & 0.01 & - & $\mathrm{N}$ & $\mathrm{N}$ & $\mathrm{N}$ \\
\hline Healthy Lunch And Lifestyle Project & 0.01 & - & $\mathrm{N}$ & $\mathrm{N}$ & $\mathrm{N}$ \\
\hline Hesperia USD & 0.01 & - & $\mathrm{N}$ & Y & Y \\
\hline Happy Valley Conference Center & 0.01 & - & $\mathrm{N}$ & $\mathrm{N}$ & $\mathrm{N}$ \\
\hline Taft City School District & 0.00 & - & $\mathrm{N}$ & $\mathrm{Y}$ & Y \\
\hline Arcata School District & 0.00 & - & $\mathrm{N}$ & $\mathrm{Y}$ & $\mathrm{Y}$ \\
\hline Celebrations Catering & 0.00 & - & $\mathrm{N}$ & $\mathrm{N}$ & $\mathrm{N}$ \\
\hline Yosemite Unified School District & 0.00 & - & $\mathrm{N}$ & $\mathrm{Y}$ & $\mathrm{Y}$ \\
\hline
\end{tabular}

Notes: The table lists the 45 vendors that contracted with schools during the 2008-2009 to 2013-2014 school years. The Healthy Eating Index scores for each vendor are based on lunch menus and calculated by nutritionists at the Nutrition Policy Institute. The percent of students served by each vendor is determined by first summing the number of students in our panel that take the end of year academic (STAR) test who are in schools being served by an outside vendor for the test year, and then dividing this total by the number of students who have their meals provided by each vendor. 


\section{Table A2: Test-Taker Covariates for Schools that Contract with School Lunch Vendors}

\begin{tabular}{|c|c|c|c|c|c|c|}
\hline \multirow[t]{2}{*}{ Sample: } & \multicolumn{3}{|c|}{ All School Sample } & \multicolumn{3}{|c|}{ Contract School Sample } \\
\hline & $(1)$ & $(2)$ & (3) & (4) & $(5)$ & $(6)$ \\
\hline Dependent Variable: & Vendor & No Vendor & Difference & Healthy & Standard & Difference \\
\hline Disadvantaged & 0.461 & 0.528 & $\begin{array}{c}-0.067 * * * \\
(0.012)\end{array}$ & 0.386 & 0.397 & $\begin{array}{c}-0.011 \\
(0.027)\end{array}$ \\
\hline Asian & 0.079 & 0.053 & $\begin{array}{c}0.026 * * * \\
(0.004)\end{array}$ & 0.028 & 0.091 & $\begin{array}{c}-0.063 * * * \\
(0.010)\end{array}$ \\
\hline White & 0.381 & 0.444 & $\begin{array}{c}-0.062 * * * \\
(0.012)\end{array}$ & 0.362 & 0.318 & $\begin{array}{c}0.044 * \\
(0.023)\end{array}$ \\
\hline Hispanic & 0.407 & 0.406 & $\begin{array}{c}0.001 \\
(0.012)\end{array}$ & 0.283 & 0.375 & $\begin{array}{c}-0.092 * * * \\
(0.027)\end{array}$ \\
\hline Black & 0.055 & 0.040 & $\begin{array}{c}0.014 * * * \\
(0.003)\end{array}$ & 0.077 & 0.033 & $\begin{array}{c}0.044 * * * \\
(0.009)\end{array}$ \\
\hline English Learner & 0.216 & 0.196 & $\begin{array}{l}0.020 * * \\
(0.008)\end{array}$ & 0.130 & 0.217 & $\begin{array}{c}-0.087 * * * \\
(0.016)\end{array}$ \\
\hline Districts & 578 & 4620 & & 229 & 405 & \\
\hline
\end{tabular}

Notes: Percentages are calculated by dividing the number of enrolled students in a given category by the total number of enrolled students in a district as reported by the California Department of Education. Standard errors reported in parentheses. The contract sample is the subset of districts that contract with any vendor at any point during our sample. ${ }^{*} \mathrm{p}<0.10,{ }^{* *} \mathrm{p}<$ $0.5,{ }^{* * *} \mathrm{p}<0.01$ 
Table A3: The Effect of Vendor Choice on Standardized Test Scores (Unweighted)

\begin{tabular}{|c|c|c|c|c|c|c|}
\hline \multirow{3}{*}{$\begin{array}{l}\text { Dependent variable: } \\
\text { Sample: }\end{array}$} & \multicolumn{6}{|c|}{ Standardized Test Score } \\
\hline & \multicolumn{3}{|c|}{ All Schools } & \multicolumn{3}{|c|}{ Contract Schools } \\
\hline & (1) & $(2)$ & (3) & (4) & (5) & (6) \\
\hline Healthy Vendor & $\begin{array}{l}0.029 * * * \\
(0.009)\end{array}$ & $\begin{array}{l}0.029 * * * \\
(0.009)\end{array}$ & $\begin{array}{l}0.029 * * * \\
(0.009)\end{array}$ & $\begin{array}{l}0.038 * * * \\
(0.008)\end{array}$ & $\begin{array}{c}0.028^{* * * *} \\
(0.009)\end{array}$ & $\begin{array}{l}0.023 * * * \\
(0.008)\end{array}$ \\
\hline Standard Vendor & $\begin{array}{l}-0.002 \\
(0.011)\end{array}$ & $\begin{array}{l}-0.003 \\
(0.012)\end{array}$ & $\begin{array}{l}-0.003 \\
(0.012)\end{array}$ & $\begin{array}{c}0.013 \\
(0.009)\end{array}$ & $\begin{array}{l}-0.006 \\
(0.012)\end{array}$ & $\begin{array}{l}-0.005 \\
(0.012)\end{array}$ \\
\hline $\begin{array}{l}\text { School-by-grade FEs } \\
\text { Covariates included }\end{array}$ & & $\mathrm{X}$ & $\begin{array}{l}X \\
X\end{array}$ & & $\mathrm{X}$ & $\begin{array}{l}X \\
X\end{array}$ \\
\hline $\mathrm{R}^{2}$ & 0.615 & 0.909 & 0.909 & 0.700 & 0.904 & 0.904 \\
\hline $\mathrm{N}$ & 174,818 & 174,818 & 174,818 & 22,162 & 22,162 & 22,162 \\
\hline Schools & 9,719 & 9,719 & 9,719 & 1,189 & 1,189 & 1,189 \\
\hline
\end{tabular}

